\title{
Promoting healthy lifestyles in Brazil: design and method of "VAMOS Program" in public health system
}

\author{
Promoção de estilos de vida saudáveis no Brasil: design e método do "Programa \\ VAMOS" no sistema público de saúde
}

\section{AUTHOR'S \\ Camila Tomicki ${ }^{1}$ (D) \\ Cassiano Ricardo $\operatorname{Rech}^{1}$ (D) \\ Lisandra Maria Konrad ${ }^{1}$ (D) \\ Elaine Cristina Maciel $^{1}$ (D) \\ Fabio Araujo Almeida ${ }^{2}$ (D) \\ Tânia Rosane Bertoldo Benedetti ${ }^{1}$ \\ 1 Federal University of Santa Catarina, Postgraduate Prooram in Physical Education, Laboratory for the Study of the Environment, Behavior Change and Aging. Florianopolis, Santa Catarina, Brazil. 2 University of Nebraska Medical Center, College of Public Health, Department of Health Promotion, Social and Behavioral Health. Omaha, Nebraska, United States.}

\section{CORRESPONDING}

\section{Camila Tomicki}

camitomicki@gmail.com

Federal University of Santa Catarina, University Campus, Trindade, Physical Education Department. Florianopolis, Santa Catarina, Brazil.

Zip code: 88040-900.

DOI

10.12820/rbafs.26e0182

\section{(cc) BY}

This work is licensed under a Creative Commons Attribution 4.0 International License.

\begin{abstract}
The "Programa Vida Ativa Melhorando a Saúde - VAMOS" (Active Life Improving Health) is a community intervention with a behavioral approach. It uses educational strategies to assist health professionals in support the population about the importance of adherence and maintenance of healthy lifestyles. This descriptive study shows the design and method of the VAMOS Program version 2.0. The intervention is for adults and older adults' users of Brazilian public health and aims to motivate them to adopt an active and healthy lifestyle regarding physical activity and eating. The program follows an intervention design that considers the dimensions of the RE-AIM framework. The VAMOS Program version 2.0 has the potential to be offered as a health promotion tool in the Brazilian public health system by using available resources and accessible and healthy behavioral strategies.

Keywords: Public health; Intervention; Behavior change; Physical activity; Healthy eating; Brazil.

RESUMO

O "Programa Vida Ativa Melhorando a Saúde - VAMOS" é uma intervenção comunitária com abordagem comportamental. Utiliza estratégias educativas para auxiliar os profissionais de saúde a orientar a população sobre a importância da adesão e manutenção de estilos de vida saudáveis. Este estudo descritivo apresenta o design e método do Programa VAMOS, versão 2.0. A intervenção é voltada para adultos e idosos usuários da saúde pública brasileira e visa motivá-los a adotarem um estilo de vida ativo e saudável no que diz respeito à atividade física e à alimentação. O programa segue um design de intervenção que considera as dimensões da ferramenta RE-AIM. O Programa VAMOS, versão 2.0, tem potencial para ser oferecido como ferramenta de promoção da saúde no sistema público de saúde brasileiro por meio da utilizaçẫo de recursos disponíveis e acessiveis e estratégias comportamentais saudáveis.
\end{abstract}

Palavras-chave: Saúde pública; Intervenção; Mudança de comportamento; Atividade física; Alimentação saudável; Brasil.

\section{Introduction}

National data shows that leisure-time physical activity levels are still low among Brazilians (only 39\% of the population) with approximately $55 \%$ of the population being considered overweight/obesity ${ }^{1}$. Despite $53.8 \%$ of the programs promote physical activity and healthy eating ${ }^{2}$, the prevalence of physical inactivity and inadequate nutrition remain high in Brazil ${ }^{1}$. These data reveal the importance of new technologies in health education since behavior change techniques can have a positive impact on the maintenance of a more active and healthier lifestyle. Thus, the VAMOS Program version 2.0 seeks to improve population health by encouraging the practice of physical activity and healthy eating. Therefore, this study aimed to describe the VAMOS Program's design and intervention method, version 2.0, implemented in the Primary Health Care (known in Brazil as APS). 


\section{Methods}

In 2011, the first version of the VAMOS Program (1.0) was created and named "VIA: Vida Ativa" (Active Life) $)^{3,4}$ based on the North American program known as "Active Living Every Day". After cultural adaptations, the program was offered in 2012, focusing on the promotion of physical activity for a group of older adults users of Basic Health Units (known in Brazil as UBS) located in southern Brazil. In 2014, the second version, named "Active Life Improving Health" (VAMOS), was developed, expanding the target population (adults and the older adults) and including the theme of healthy eating.

The VAMOS Program version 2.0 is a behavior change program ${ }^{6}$, based on Albert Bandura's Sociocognitive Theory ${ }^{7}$, that aims to motivate people to adopt an active and healthy lifestyle regarding physical activity and eating. To achieve this, the following goals were defined: 1) to reach the largest number of people exposed to noncommunicable chronic diseases (NCDs) risk factors; 2) to help participants to increase physical activity levels, reduce sedentary behavior time, increase consumption of fresh and minimally processed foods, decrease consumption of processed and ultra-processed foods, reduce body mass and improve the perception of the quality of life; 3) to be flexible to be adopted in any region and context in Brazil; 4) to lead to the maintenance of the changes made by participants during the program. The mission of the VAMOS Program version 2.0 is to be a national model and its philosophy is based on the development of attitudes, skills, and competencies to promote autonomy when choosing an active and healthy lifestyle, valuing cultural contexts.

The program is designed for the Brazilian population meeting the following criteria: 1 ) ages $\geq 18$ years; 2 ) present NCDs risk factors (sedentary lifestyle, unhealthy diet); and 3) be overweight/obese (body mass index $\geq$ $25 \mathrm{~kg} / \mathrm{m}^{2}$ ). To disseminate the VAMOS Program version 2.0 and reach the target population, the following recruitment strategies were adopted: posters distributed in the community where the program is proposed; verbal invitation and/or distribution of business cards and/ or flyers by professionals involved in the program implementation. The recruitment period lasts 20-30 days and a meeting is held with stakeholders at a pre-set date and time to clarify program objectives and screen participants.

The VAMOS Program version 2.0 includes 12 faceto-face meetings that can be held weekly or biweekly, totaling a period of three to five months of intervention.
The educational material consists of 12 printed booklets that include content, objectives, and activities to help participants understand the need for behavior change for an active and healthy lifestyle, as well as to promote and maintain them. The logical model of the VAMOS Program ${ }^{6}$ shows the didactic material structured as follows: Meeting 1 - Introduction: To show the program and educational material. Meeting 2 - Let's prepare ourselves? To record changes already made, understand the concepts of physical activity, exercise, and healthy eating habits, and identify the desire to change and the benefits of a healthy life. Meeting 3 - Let's find out more about healthy eating habits? To increase knowledge about what healthy eating habits are and how this can become part of your routine. Meeting 4 - Let's decide and practice? To reflect on finding time for physical activity, understanding different physical activity levels, preparing a plan, and monitoring physical activity. Meeting 5 - Let's overcome challenges? To identify obstacles for healthy eating habits and more active life and to reflect on solutions. Meeting 6 - Let's establish goals? To set goals, to plan to monitor, and to keep positive messages in mind. In this meeting, each participant receives a pedometer as a stimulus for self-monitoring of physical activities. Meeting 7 - Let's obtain support and go step by step? To identify the main sources of support, review the physical activity plan, and present the pedometer as a self-monitoring strategy. Meeting 8 - Let's become more confident and to revise the goals? To assess progress, to re-establish new goals for eating habits, to raise awareness of the importance of trusting actions, always keeping in mind positive messages and the role of stretching exercises. Meeting 9 - Let's face the obstacles? To identify and to recognize obstacles to behavioral change and to raise awareness of the importance of preparing for risky situations and the role of muscle-strengthening activities. Meeting $10-$ Let's reduce stress? To identify stressful situations and to learn stress-reducing techniques and ways to manage time. Meeting 11 - Let's find out new opportunities to have a healthy life? To identify new options for being physically active, have healthier eating habits, and make healthier choices last longer. Meeting 12 - Let's make lasting changes? To celebrate achievements, identify strategies that work for each participant, reflect on ways to solve problems, and commit to maintaining new behavior types. Additionally, an extra booklet is provided with information and reinforcement activities, and suggestions for physical activity.

The program is offered by certified healthcare pro- 
fessionals who have participated in a 20 -hour online training program. Each meeting is conducted according to the following protocol: 1) environment preparation: adequate physical space to accommodate up to 25 participants seated in chairs arranged in a circle; 2) reception of participants: the health professional establishes a friendly and empathetic relationship with the participants, punctuality is emphasized and the frequency recorded; 3) meeting: it lasts from 90 to 120 minutes, is conducted by the trained health professional and following an expository-dialogue approach, using the booklet as reference. This booklet is freely available for participants at the beginning of each meeting. 4) snacks: as a strategy for sharing experiences and social support at the end of each meeting, healthy food snacks prepared by participants are offered.

To measure impact, the program follows an intervention design that considers the dimensions of the RE-AIM framework ${ }^{8,9}$ (Figure 1). Assessments are carried out at the organizational level (with health professionals) and individual participation (intervention group x control group). Data collection follows four stages: pre-intervention, post-intervention, 6-month follow-up, and 1 year after the end of the intervention.
The entire research process was approved by the Human Research Ethics Committee (No. 1.394.492/2016).

\section{Results}

Considering the 2014-2019 period, the VAMOS Program version 2.0 has already been offered in the South, Southeast, Midwest, and Northeast involving five states of Brazil and eight cities and included 490 participants, 44 health professionals from various areas, and 15 UBS.

Until now, program participants demonstrated ${ }^{10-12}$ : (a) reduction in sedentary behavior, (b) increase in light physical activity and increase in moderate/vigorous physical activity behavior, (c) reduction in the consumption of processed and ultra-processed foods and increased consumption of fresh and minimally processed foods, (d) reduction in body mass and waist circumference, (e) improved of blood pressure and microvascular reactivity, (f) increased perception of the quality of life, and $(\mathrm{g})$ improved self-esteem. Also, the program retained more than half of the participants $(51.9 \%)^{13}$.

\section{Adverse Effects}

The implementation protocol could not always be followed, as it depended on the locals and the professio-

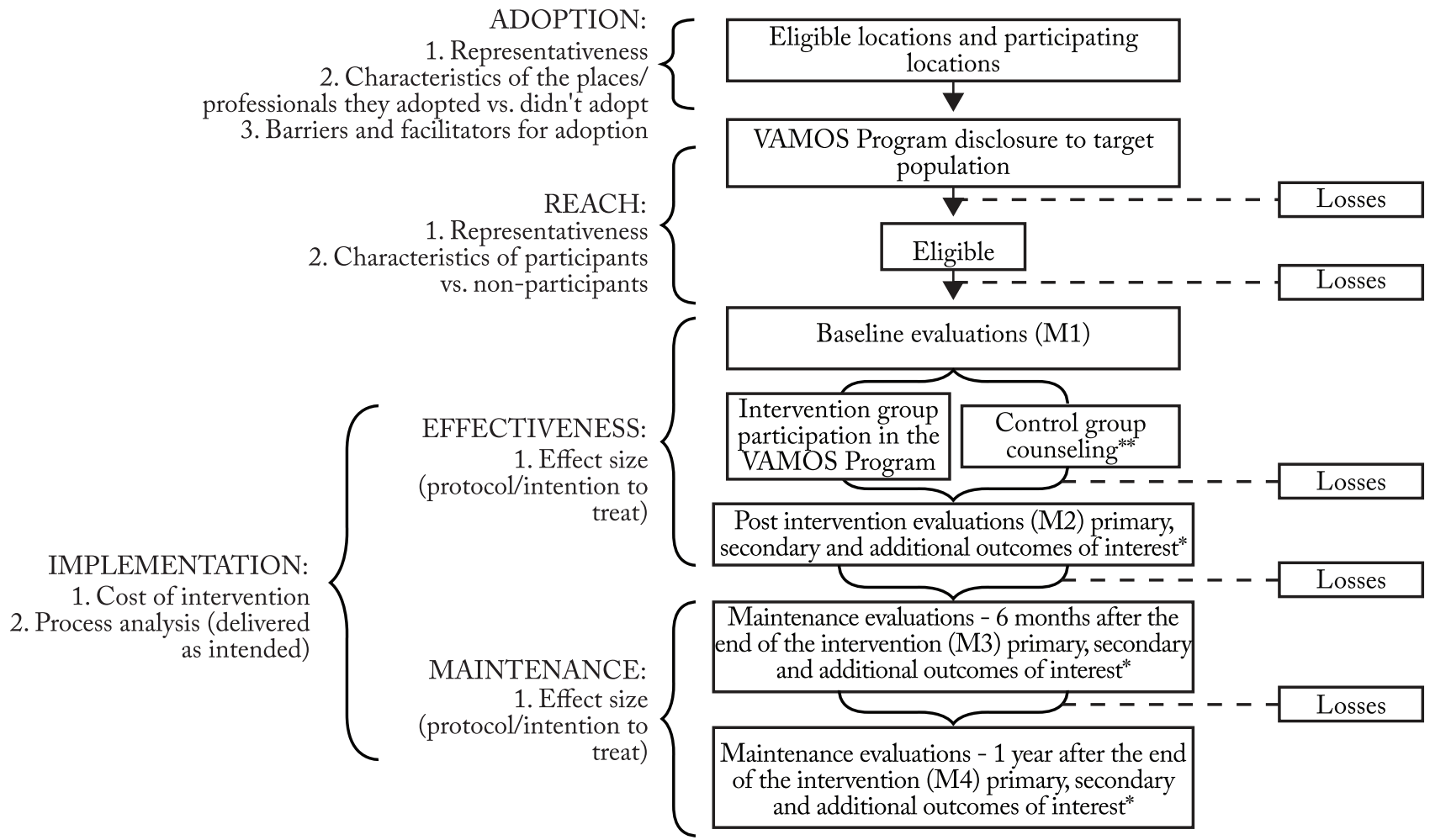

Figure 1 - Flow chart of the design of the evaluation of VAMOS Program version 2.0 considering the RE-AIM framework. Label: M1 = Moment 1. M2 = Moment 2. M3 = Moment 3. M4 = Moment 4. ${ }^{*}$ Primary outcomes: physical activity and food; secondary outcomes: body mass and quality of life; additional outcomes of interest: sociodemographic, clinical, environmental data, among others. ${ }^{* *}$ The control group receives brief information about the importance of acquiring and maintaining healthy behaviors related to physical activity and healthy eating. 
nals' agendas. Adaptations were observed in the environment and the duration of the meetings. Different strategies were adopted, considering the context and culture of the community. Also, a healthy snack was not always made according to the protocol.

\section{Sustainability}

The VAMOS Program version 2.0 offers subsidies to health professionals for program implementation and participants for autonomy acquisition, aimed at adherence and maintenance of an active and healthy lifestyle. It is a unique proposal for health promotion in the Brazilian context, which at its core is education as the basis for behavior change. Thus, due to the need for effective, lasting, and innovative interventions that enable easy access to the population, this program has the potential for broad reach and sustainability in the Brazilian public health system. The sustainability of the VAMOS Program version 2.0 in Unified Health System (known in Brazil as SUS) was proven through a framework of the Science of Dissemination and Implementation - RE-AIM ${ }^{8,9}$, which is used internationally to plan and evaluate programs aiming to increase the impact of its interventions in public health.

\section{Public Health Significance}

The guidelines of the SUS ${ }^{14}$ guide its professionals to develop actions for the primary prevention of NCDs and health promotion, especially in APS. However, there is a lack of interventions with this focus on public health.

Thus, considering the growing global NCDs epidemic, the VAMOS Program version 2.0 has the potential to be offered as a health promotion tool in the SUS by using available resources and accessible and healthy behavioral strategies. Results have shown important changes in the health of participants and offered health providers the necessary skills for further dissemination and implementation of the program in the Brazilian public health system.

It is understood that the proposed public health interventions need to be aligned with the needs of the population ${ }^{15}$. This is in line with the proposal of the VAMOS Program version 2.0, which is innovative. With a preventive character and a differentiated approach, based on health education, with behavior change strategies and themes aimed at two essential areas of health - physical activity and healthy eating, the program stands out for its comprehensive health promotion protocol.

\section{Conclusion}

The Program VAMOS - version 2.0 design and method and results from its implementation highlight the importance of planning effective public health interventions.

\section{Conflict of interest}

The authors declare no conflict of interest.

\section{Funding}

This study was supported by Coordenação de Aperfeiçoamento de Pessoal de Nivel Superior - Brasil (CAPES) - Finance Code 001.

\section{Clinical trials}

This study is registered on the Clinical Trials site (https://clinicaltrials.gov) - identifier NCT02823301.

\section{Authors' contributions:}

Tomicki C and Konrad LM participated in the initial study design, data analysis and interpretation, writing and critical review of the text. Rech CR contributed to the writing of the text and critical review of the intellectual content. Maciel EC contributed to the writing and critical review of the text. Almeida FA contributed to the critical review of intellectual content. Benedetti TRB participated in the initial design of the study, contributed to the writing and critical review of the intellectual content and approved the final version.

\section{References}

1. Brasil. Vigitel Brasil 2019: vigilância de fatores de risco e proteção para doenças crônicas por inquérito telefônico: estimativas sobre frequência e distribuição sociodemográfica de fatores de risco e proteção para doenças crônicas nas capitais dos 26 estados brasileiros e no Distrito Federal em 2019. Brasília, Brasil: Ministério da Saúde; 2020.

2. Konrad LM, Tomicki C, Silva M, Almeida FA, Benedetti TRB. Evaluation of behavior change programs using the REAIM framework: a systematic review study. Rev Bras Ativ Fís Saúde. 2017;22(5):439-49.

3. Benedetti TRB, Rech CR, Konrad LM, Almeida FA, Brito FA, Chodzko-Zajko W, et al. Re-thinking physical activity programs for older Brazilians and the role of public health centers: A randomized controlled trial using the RE-AIM model. Front Public Health. 2020;8(48):1-11.

4. Benedetti TRB, Schwingel A, Gomez LSR, Chodzko-Zajko W. Program "VAMOS" (Active Living, Enhancing Health): From conception to initial findings. Rev Bras Cineantropom Desempenho Hum. 2012;14(6):723-37.

5. Blair SN, Dunn AL, Marcus BH, Carpenter RA, Jaret P. Active Living Every Day. Champaign, IL: Human Kinetics, 2010.

6. Benedetti TRB, Manta SW, Gomez LSR, Rech CR. Logical model of a behavior change program for community intervention - Active Life Improving Health - VAMOS. Rev Bras Ativ Fís Saúde. 2017;22(3):309-13.

7. Bandura A. Social foundations of thought and action: a social cognitive theory. Englewood Cliffs: Prentice-Hall, 1986.

8. Almeida FA, Brito FA, Estabrooks PA. RE-AIM framework: Translation and cultural adaptation to Brazil. Refacs. 2013;1(1):6-16. 
9. Brito FA, Benedetti TRB, Tomicki C, Konrad LM, Sandreschi PF, Manta SW, et al. Translation and adaptation of the RE-AIM Check List for Brazilian reality. Rev Bras Ativ Fís Saúde. 2018;23(e0033):1-8.

10. Gerage AM, Benedetti TRB, Ritti-Dias RM, Santos ACO, Souza BC, Almeida FA. Effectiveness of a behavior change program on physical activity and eating habits in patients with hypertension: a randomized controlled trial. J Phys Act Health. 2017;14(12):943-52.

11. Meurer ST, Lopes ACS, Almeida FA, Mendonça RD, Benedetti TRB. Effectiveness of the VAMOS strategy for increasing physical activity and healthy dietary habits: a randomized controlled community trial. Health Educ Behav. 2019;46(3):406-16.

12. Gerage AM, Benedetti TRB, Cavalcante BR, Farah $B Q$, Ritti-Dias RM. Efficacy of a behavior change program on cardiovascular parameters in patients with hypertension: a randomized controlled trial. Einstein (Sao Paulo). 2020;18(eAO5227):1-8.
13. Konrad LM, Tomicki C, Ribeiro CG, Bezerra JB, Maciel EC, Rech CR, et al. Length of stay in a behavior change program in primary health care: "VAMOS" Program. Rev Bras Ativ Fis Saúde. 2019;24:e0090.

14. Ministério da Saúde. Portaria no 2.436, de 21 de setembro de 2017. Aprova a Política Nacional de Atenção Básica, estabelecendo a revisão de diretrizes para a organização da Atenção Básica, no âmbito do Sistema Único de Saúde (SUS). Brasília, Brasil: Ministério da Saúde; 2017.

15. Ferreira RW, Caputo EL, Häfele CA, Jerônimo JS, Florindo AA, Knuth AG, et al. Acesso aos programas públicos de atividade física no Brasil: Pesquisa Nacional de Saúde, 2013. Cad. Saúde Pública. 2019;35(2):e00008618.

Received: $10 / 08 / 2020$ Approved: 20/01/2021

\section{Quote this article as:}

Tomicki C, Rech CR, Konrad LM, Maciel EC, Almeida FA, Benedetti TRB. Promoting healthy lifestyles in Brazil: design and method of "VAMOS Program" in public health system. Rev Bras Ativ Fís Saúde. 2021;26:e0182. DOI: 10.12820/rbafs.26e0182 